\title{
Surgical Management of Severe Hidradenitis Suppurativa in Women: Outcome and Quality of Life Assessment
}

\author{
Dana Sawan ${ }^{1,2 *}$, Cyril Touboul ${ }^{3}$, Barbara Hersant ${ }^{1}$, Jean Paul Meningaud1 \\ ${ }^{1}$ Aesthetic and Reconstructive Plastic Surgery Unit of Henri Mondor Hospital, Créteil, France \\ ${ }^{2}$ Department of Obstetrics and Gynaecology, Faculty of Medicine, King Abdulaziz University, Jeddah, Saudi Arabia \\ ${ }^{3}$ Gynaecology and Reproduction Medicine Unit of Tenon Hospital, Paris, France \\ Email: *dsawan@kau.edu.sa
}

How to cite this paper: Sawan, D., Touboul, C., Hersant, B. and Meningaud, J.P. (2021) Surgical Management of Severe Hidradenitis Suppurativa in Women: Outcome and Quality of Life Assessment. Open Journal of Obstetrics and Gynecology, 11, 1425-1436.

https://doi.org/10.4236/ojog.2021.1111132

Received: August 13, 2021

Accepted: November 5, 2021

Published: November 8, 2021

Copyright $\odot 2021$ by author(s) and Scientific Research Publishing Inc. This work is licensed under the Creative Commons Attribution International License (CC BY 4.0).

http://creativecommons.org/licenses/by/4.0/

\begin{abstract}
Background: Hidradenitis suppurativa (HS) or Acne inversa sometimes referred to as Verneuil's disease, is a rare and debilitating condition arising in the intertriginous folds that bear apocrine glands (axillae, groin, perineum, pubis, ano-genital area). It has a deleterious impact on the life of affected persons who tend to be more depressive and poorly socially and sexually connected because of pain, malodor and stigmatization. Methods: We conducted a retrospective study in Henri Mondor Hospital in Créteil, France, in order to assess the effectiveness of surgery as a radical treatment and also assess the factors related to recurrence and the surgical and sexual satisfaction in women operated for severe HS of perineum and genitalia. Results: Fifty-five women were included. We got a recurrence rate of $23.6 \% .66 .7 \%$ of recurrence occurred after localized excision. $83 \%$ of patients were satisfied with surgery results and would undergo a revision surgery or recommend it. The factors significantly associated with recurrence were overweight $(\mathrm{p}=$ $0.0046)$, location in groin $(p=0.0040)$, localized excision $(p=0.02)$, total excision $(\mathrm{p}=0.009)$, healing via secondary intention $(\mathrm{p}=0.001)$ and disability due to HS ( $\mathrm{p}=0.006)$. Assessment of sexual response thanks to the FSFI showed an alteration of all the domains of sexual response but the composite index of 18.51 was below the threshold to diagnose pathologic sexual condition.
\end{abstract}

\section{Keywords}

Hidradenitis Suppurativa, Acne Inversa, Wide Excision, Recurrence, Surgical Satisfaction, Female Sexual Function Index

\section{Introduction}

Hidradenitis suppurativa (HS), also called Acne inversa or Verneuil's disease, 
was first described by Velpeau in 1839. Verneuil named the condition and associated it with sweat glands in 1854. It is in 1939 that the relation with apocrine glands was described by Brunstig [1] [2]. It is a chronic and recurrent condition arising in apocrine gland bearing skin in the body folds, especially the groin and the armpit, causing painful abscesses and scarring. At the beginning, it presents as subcutaneous nodules. Later, those nodules may coalesce to form dermal painful abscesses or rupture leading to purulent and offensive smelling discharge. Finally, the abscesses heal with a lot of fibrosis, dermal contractures and skin induration. The characteristic features of HS are double comedones (blackheads with multiple apertures communicating below the skin), sinus tracts (resulting in the reepithelization of hair follicles after their rupture following occlusion) that shelter bacteria of foreign bodies and abscesses [1] [3].

The diagnosis of HS is clinical and requires no biopsy or other analysis and is based on the frame of recurrent/chronic disease, failure to heal completely with antibiotics, multifocal distribution, sinus formation, scarring and dermal contractures, presence of double comedones, multiple open comedones, nodules, papules, tenderness of lesions and purulent discharge [4] [5]. The treatment alternatives for HS include general and topical antibiotics (Tetracyclin, Clindamycin), retinoids, immunosuppressants, antiandrogens and surgery [6]. In 2017, Deckers undertook a study on a sample of 84 HS patients. A total of 253 surgical procedures were performed. The recurrence rate was as high as $37.6 \%$ after a mean follow up time of 3 years while the total remission rate was 49 years. The main recurrence factor was location in anogenital area [7]. On the other hand, Wolkenstein et al. studied the quality-of-life impairment in $61 \mathrm{HS}$ patients. They found that the said impairment was much greater than in any other dermatological condition [8].

The occurrence of HS in the groin and perineum is accompanied with lots of pains, social embarrassment. Compared to other skin lesions, HS impacts most negatively on the quality of life [9]. The present study is a retrospective review of severe HS of female perineum and genitalia surgically treated with focus on the outcomes and impact on the quality of postoperative life.

\section{Methods}

\subsection{Study Design and Place}

We carried out a cross sectional retrospective study of the charts of patients operated for HS of perineum and genitalia in Henri Mondor Teaching Hospital in Créteil, France.

\subsection{Duration}

We reviewed the charts of patients on a 19-month period spanning from December 2017 to June 2019.

\subsection{Sampling}

We consecutively recruited all the files of patients meeting our inclusion criteria: 
patients operated for severe HS of perineum and genitalia.

\subsection{Data Collection}

We retrieved files from the electronic database of the Plastic Surgery Theater of Henri Mondor Teaching Hospital information regarding epidemiologic characteristics of the patients (Age, sex, weight, body mass index), clinical features of the disease (location, history of pain, discharge, previous surgery, treatments received, Hurley stage), type of surgery done (Incision and drainage, localized or total excision), subsequent repairs and complications if any.

The patient satisfaction was assessed thanks to the Surgical Satisfaction questionnaire (SSQ) [10] adapted to our work by additional questions. We contacted the patients by email to administer the questionnaire. The latter was made of 8 questions to be responded with one of the following options: totally satisfied-partially satisfied-neutral, a bit satisfied, not satisfied at all. Furthermore, we assessed the impact of the surgery on sex life thanks to a specific questionnaire and the Female Sexual Function Index (FSFI) [11] that evaluates 6 domains of sexual response: Desire, arousal, lubrication, orgasm, satisfaction and pain. The FSFI is available for download on the website https://drdanasawan.com/wp-content/uploads/2021/10/FSFI questionnaire.pdf.

\subsection{Ethics}

Patients had to sign and return electronically an informed consent sheet prior to filling our questionnaire. The aim of the study and our expectations were explained to them on phone call. We had the authorization of the institutional Board of the Henri Mondor Hospital.

\subsection{Data Processing}

Data were analyzed thanks to SPSS 23 (IBM Corp., Armonk, N.Y., USA). We used percentage, means and standard deviation to describe the characteristics of the sample. In order to compare categorial variables, we used Chi square and Fisher tests. To compare means, we used the independent $t$ test, assuming a normal distribution of the sample. If not, Welch's $t$ test was used as alternative. The threshold for statistical significance was set at $\mathrm{p}$ value $<0.05$.

\section{Results}

\subsection{General Characteristics of Study Population}

Between December $29^{\text {th }} 2017$ and June $11^{\text {th }} 2019,61$ patients were operated for HS in Dermatology and Plastic Surgery Unit of Henri Mondor Hospital by second author $(\mathrm{BH})$ but 6 were rejected because the location of lesion was not perineum and genitalia. We then retained the 55 files that met our inclusion criteria.

All the patients were women. The mean age at operation was 29.78 years (SD 10.8) ranging from 16 to 63 years while at onset of disease it was 23.82 (SD 9.4) 
ranging from 11 to 53. As far as past medical history is concerned, 6 patients had pilonidal sinus, 4 a family history of HS and 4 acne vulgaris. The other characteristics of the patients are summarized in Table 1.

\subsection{Surgery Overview}

The lesion sites were groin $(\mathrm{N}=27,49 \%)$, vulva $(\mathrm{N}=19,34.5 \%)$, Mons pubis ( $\mathrm{N}$ $=16,29.1 \%)$ and buttock $(\mathrm{N}=8,14.8 \%)$. As far as the type of surgery is concerned, 28 patients $(50.9 \%)$ underwent localized excision while 25 (45.5\%) had wide excision and $2(3.6 \%)$ had incision and drainage. Regarding the closure method, 33 patients (60\%) had healing via secondary intention while 22 patients (40\%) had direct closure. One patient had a concomitant releasing colostomy performed.

Table 1. Characteristics of the sample.

\begin{tabular}{|c|c|c|c|c|c|}
\hline Variables & $\mathbf{N}$ & Min & $\operatorname{Max}$ & Mean & SD \\
\hline \multicolumn{6}{|l|}{ Age (years) } \\
\hline -At surgery & 55 & 16 & 63 & 29.78 & 10.8 \\
\hline -At onset & 45 & 11 & 53 & 23.82 & 9.4 \\
\hline \multicolumn{6}{|c|}{ Visual scale 0 to 10 evaluation of pain and discharge prior to surgery } \\
\hline -Pain & 26 & 0 & 9 & 4.38 & 3.3 \\
\hline \multirow[t]{3}{*}{-Discharge } & 26 & 0 & 10 & 4.77 & 2.6 \\
\hline & & & $\mathrm{N}$ & $\%$ & \\
\hline & $\mathrm{I}$ & & 3 & 5.5 & \\
\hline \multirow[t]{2}{*}{ Hurley score } & II & & 29 & 52.7 & \\
\hline & III & & 23 & 41.8 & \\
\hline \multicolumn{6}{|l|}{ Weight } \\
\hline -Overweight & & & 12 & 40.0 & \\
\hline -Obesity & & & 3 & 18.8 & \\
\hline Tobacco use & & & 25 & 53.2 & \\
\hline \multicolumn{6}{|l|}{ Past medical history } \\
\hline -Family HS & & & 4 & 7.7 & \\
\hline -Acnea & & & 4 & 7.3 & \\
\hline -Chronic Inflammatory Bowel Disease & & & 1 & 1.8 & \\
\hline -Ankylosing Spondylitis & & & 1 & 1.8 & \\
\hline -Pilonidal sinus & & & 6 & 10.9 & \\
\hline \multicolumn{6}{|l|}{ Previous surgical treatment } \\
\hline -Incision-drainage & & & 25 & 45.5 & \\
\hline -Localized Excision & & & 17 & 30.9 & \\
\hline -Wide Excision & & & 12 & 21.8 & \\
\hline
\end{tabular}




\subsection{Post-Surgical Complications}

The leading complication was recurrence of HS in 26 patients (47.27\%). Table 2 summarizes the complications encountered. The factors significantly associated with recurrence were overweight ( $\mathrm{p}=0.0046)$, location in groin $(\mathrm{p}=0.0040)$, localized excision $(p=0.02)$, total excision $(p=0.009)$, healing via secondary intention ( $p=0.001)$ and disability due to HS $(p=0.006)$. More details on the determinants of HS recurrence are given in Table 3.

\subsection{Assessment of Sexual and Surgical Satisfaction}

Thirty patients filled and returned the questionnaire. Eighty-three per cent said to be partially or completely satisfied and would recommend it to other HS patients. This same subgroup said was ready to undergo revision surgery in case of failure or recurrence. $86 \%$ of the sample believed surgery was the best management option for HS treatment. More details on surgical satisfaction are in Table 4.

\subsection{Assessment of Sexual Satisfaction}

We used the FSFI to assess sexual satisfaction after surgery. For all the domains studied, we calculated the composite index (CI) which is the sum of all the scores recorded in each single domain. We obtained a CI of 18.51 below the figure of 26.55 set as the threshold for diagnosis of sexual disorders. See details on Table 5.

Table 2. Complications of HS surgery.

\begin{tabular}{lcc}
\hline \multicolumn{1}{c}{ Total } & $\mathrm{N}$ & $\%$ \\
\hline Pain & 55 & 100.0 \\
Dehiscence & 1 & 1.8 \\
Infection & 2 & 3.6 \\
Lymphedema & 2 & 3.6 \\
Hematoma & 1 & 1.8 \\
Retraction/reduced mobility & 0 & 0 \\
Need for physiotherapy & 3 & 5.4 \\
Revision surgery & 2 & 3.6 \\
Need for re-hospitalisation & 1 & 1.8 \\
HS recurrence & 1 & 1.8 \\
$\quad$ Recurrence on same site & 26 & 47.2 \\
$\quad$ Recurrence in other site & 13 & 23.6 \\
\hline
\end{tabular}


Table 3. Factors associated with HS recurrence.

\begin{tabular}{|c|c|c|c|c|c|c|}
\hline \multirow{2}{*}{ Variables } & & \multirow{2}{*}{ Total } & \multicolumn{2}{|c|}{ HS recurrence } & \multirow{2}{*}{$\begin{array}{l}\text { Odds Ratio } \\
\text { (CI 95\%) }\end{array}$} & \multirow{2}{*}{$P$} \\
\hline & & & No & Yes & & \\
\hline \multirow{3}{*}{ Hurley prior to surgery } & I & 6 & $2(33.3 \%)$ & $4(66.7 \%)$ & & \\
\hline & II & 18 & $7(38.9 \%)$ & $11(61.1 \%)$ & - & 0.732 \\
\hline & III & 14 & $7(50.0 \%)$ & $7(50.0 \%)$ & & \\
\hline \multirow{3}{*}{ Hurley at surgery } & I & 3 & $2(66.7 \%)$ & $1(33.3 \%)$ & & \\
\hline & II & 27 & $12(44.4 \%)$ & $15(55.6 \%)$ & - & 0.595 \\
\hline & III & 23 & $13(56.5 \%)$ & $10(43.5 \%)$ & & \\
\hline Overweight & & 12 & $5(41.7 \%)$ & $7(58.3 \%)$ & $6.53(1.2-35.6)$ & $0.046^{\mathrm{b}}$ \\
\hline Obesity & & 5 & $3(60.0 \%)$ & $2(40.0 \%)$ & $1.58(0.2-11.4)$ & 0.637 \\
\hline Location: Mons pubis & & 16 & $5(31.3 \%)$ & $11(68.8 \%)$ & $3.23(0.9-11.2)$ & 0.059 \\
\hline Location: groin & & 25 & $9(36.0 \%)$ & $16(64.0 \%)$ & $3.20(1.0-9.9)$ & $0.040^{\mathrm{a}}$ \\
\hline Location: vulva & & 18 & $9(50.0 \%)$ & $9(50.0 \%)$ & $1.06(0.3-3.3)$ & 0.922 \\
\hline Location: buttock & & 8 & $5(62.5 \%)$ & $3(37.5 \%)$ & $0.60(0.1-2.8)$ & 0.705 \\
\hline Localized excision & & 27 & $9(33.3 \%)$ & $18(66.7 \%)$ & $0.26(0.1-0.8)$ & $0.020^{\mathrm{a}}$ \\
\hline Wide excision & & 25 & $17(68.0 \%)$ & $8(32.0 \%)$ & $4.49(1.4-14.2)$ & $0.009^{\mathrm{a}}$ \\
\hline Healing via secondary intention & & 32 & $22(68.8 \%)$ & $10(31.3 \%)$ & $9.35(2.5-35.0)$ & $0.001^{\mathrm{b}}$ \\
\hline $\begin{array}{l}\text { Healing via secondary intention } \\
+ \text { wound dressing }\end{array}$ & & 32 & $22(68.8 \%)$ & $10(31.3 \%)$ & $9.35(2.5-35.0)$ & $0.001^{\mathrm{b}}$ \\
\hline Direct closure & & 22 & $8(36.4 \%)$ & $14(63.6 \%)$ & $0.41(0.1-1.3)$ & 0.119 \\
\hline $\begin{array}{l}\text { Disability caused by HS (medical } \\
\text { leave, joblessness) }\end{array}$ & & 9 & $1(11.1 \%)$ & $8(88.9 \%)$ & $15.27(1.7-138.3)$ & $0.006^{\mathrm{a}}$ \\
\hline Tobacco use & & 24 & $12(50.0 \%)$ & $12(50.0 \%)$ & $1.00(0.3-3.2)$ & $>0.999$ \\
\hline
\end{tabular}

Table 4. Assessment of surgical satisfaction.

\begin{tabular}{|c|c|c|c|c|c|}
\hline Question: n (\%) & Totally satisfied & Satisfied & Neutral & Partially satisfied & Not satisfied \\
\hline 1) Are you satisfied with pain management? & $17(56.6)$ & $4(13.3)$ & $3(10)$ & $3(10)$ & $3(10)$ \\
\hline 2) Are you satisfied with wound management? & $18(60)$ & $3(10)$ & $4(13.3)$ & $3(10)$ & $2(6.6)$ \\
\hline $\begin{array}{l}\text { 3) Are you satisfied with management of offensive } \\
\text { odours? }\end{array}$ & $18(60)$ & $4(13.3)$ & $4(13.3)$ & $2(6.6)$ & $2(6.6)$ \\
\hline 4) If recurrence, would you undergo revision surgery? & $20(66.6)$ & $5(16.6)$ & $2(6.6)$ & $1(3.3)$ & $2(6.6)$ \\
\hline 5) Are you satisfied with your medical leave? & $22(73.3)$ & $3(10)$ & $2(6.6)$ & $1(3.3)$ & $2(6.6)$ \\
\hline 6) Are you satisfied with the results of the surgery? & $20(66.6)$ & $5(16.6)$ & $3(10)$ & 0 & $2(6.6)$ \\
\hline $\begin{array}{l}\text { 7) After this surgery, do you think it was the best } \\
\text { treatment for you and would you undergo revision } \\
\text { surgery in case of recurrence? }\end{array}$ & $24(80)$ & $2(6.6)$ & $1(3.3)$ & $1(3.3)$ & $2(6.6)$ \\
\hline 8) Would you advise another HS patient to be operated? & $22(73.3)$ & $3(10)$ & $2(6.6)$ & $1(3.3)$ & $2(6.6)$ \\
\hline
\end{tabular}


Table 5. Results for the assessment of sexual satisfaction with SFSI.

\begin{tabular}{ccccccc}
\hline Domain & Desire & Arousal & Lubrication & Orgasm & Satisfaction & Pain \\
\hline Score & 2.67 & 2.83 & 3.15 & 3.02 & 3.26 & 3.58 \\
\hline
\end{tabular}

\section{Discussion}

We carried out a retrospective review of the files of 55 women operated for severe perineal or genital HS in Henri Mondor Teaching Hospital in Créteil between December 2017 and June 2019. The mean age at surgery was 29.78 years. $96.4 \%$ of the patients had localized or wide surgical excision and $3.6 \%$ an incision and drainage. We recorded a $49.1 \%$ rate of recurrence associated with overweight, location on groin, localized excision, total excision, healing via secondary intention and disability due to HS. $83 \%$ of the patients were satisfied with the surgery and would recommend it or accept revision surgery while the post-surgery composite index for sexual satisfaction was 18.51 meaning no pathologic sexual disorder.

The etiology of HS is still controversial. But the understanding of the disease has changed over time. After an initial theory by Verneuil that incriminated sweat glands for over a century, Brunstig suggested that apocrine glands be blamed for it [1]. Many etiopathogenic factors have since been reported: genetic (one form has autosomal dominant transmission), endocrinologic (high androgen levels), environmental (shaving, friction), bacterial, pharmacological (lithium), obesity and smoking [1] [12] [13].

This disease usually starts in the second or third decade and is rare after menopause. Its prevalence ranges from 0.00033 in clinical data to $4.1 \%$ in pathological reports [1] [14]. It occurs predominantly in women with a sex ratio ranging from 2 to 5 women for a man that is yet to be explained [14]. It has no racial predilection [15] [16] [17] though some authors in limited studies have reported African Americans and Caribbeans to be more prone to develop HS [18] [19].

The diagnosis of HS is clinical. Its differential diagnosis is done with some conditions including but not limited to Chron's disease, granuloma inguinale, cellulitis, anal fistula, lymphadenopathy and tuberculous abscess [1] [20].

Hurley was the first to propose a staging system for HS that was surgery-oriented [21]. Later on, Sartorius proposed another classification, more suited for clinical trials and their outcomes [22]. More recent staging systems have been proposed but are not yet widespread. They include Physician Global Assessment (PGA) and Hidradenitis suppurativa Clinical Response (HiSCR) [3].

As the disease worsens over stages, it not only destroys patients tissues but also take away their quality of life especially because of pain, discomfort, offensive odors, multiple or long medical leaves, fear of social interactions, low self-esteem, stigmatization and work disability [1] [23] [24] [25].

The treatment of earlier stages HS is behavioral and medical and include education of patients to encourage self-watch and management, wearing of loose 
clothes to avoid friction in intertriginous folds, weight loss, tobacco cessation and cleanliness to reduce odor, topical treatment, intralesional corticosteroids and antibiotics (Doxycycline, tetracycline or Clindamycin) [1] [3] [13]. In past years, radiotherapy was used in earlier stages with some success [1]. Severe disease requires more aggressive treatments like Carbon dioxide or YAG evaporation of diseased tissues and radical surgery. In 2015, an expert panel issued European Guidelines for the treatment of HS/acnea inversa recommending that HS be treated based on its subjective impact and its objective severity using surgery to cure locally recurrent lesions while medical therapy (including antibiotics and immunosuppressants) in combination with surgery be used for wide spread lesions [12] [13].

Recurrence is a well-known feature of HS. Our recurrence rate on same site is (23.6\%). Ulrich et al. found a recurrence rate of $12.5 \%$ in a German series of 84 patients, significantly higher in heavy smokers [26]. Deckers et al. reported $37.6 \%$ recurrence rate after a 3 -year long follow-up in a series of 84 patients who underwent 253 procedures [7]. Other authors report lower recurrence rates. The difference lies in the heterogeneity of the samples since the initial severity, patients' comorbidities, location of the disease, extent of the involvement and surgical techniques are important determinants of recurrence [1] [12]. In fact, Mehdizadeh et al. in a meta-analysis and review reported that wide excision is the best surgical technique whenever possible as it lowers the recurrence rate [27]. However, there is no consensus on the preferred surgical technique and it is not always possible to perform a wide excision in some locations like groins, buttocks perineum and genitalia [1] [6].

We registered a post-surgical satisfaction rate of $83 \%$. Those patients said would recommend surgery to others or undertake revision surgery in case of failure or recurrence. The retrospective nature of the study did not permit to get the preoperative assessment of the quality of life. However the postoperative survey revealed an overall improvement of the quality of life through abovementioned high satisfaction rates. Kouris et al. in a study compared 94 HS patients with 94 controls and found that the cases had statistically significantly higher anxiety, depression, loneliness and social isolation scores than their control counterparts [23]. In the same vein, Alavi et al. found that patients with high odor had a greater quality of life impairment and concluded that malodor was a symptom of HS that significantly impairs the QoL of affected persons [28]. In this study sample, only $13.2 \%$ of patients were not satisfied.

Regarding sexual life, all the compartments of sex response were adversely affected by HS, but there was a general postoperatively satisfaction since the composite index for SFSI was within normal range. This is comprehensible since our sample included only severe cases that already faced the worst symptoms of HS (purulent discharge, malodor, disability). Janse et al. surveyed 300 patients of HS on their sexual health and QoL and reported a diminished QoL and sexual health in this population according to FSFI, ASEX and IIEF scores [24]. Fur- 
thermore, sexual life was associated with QoL in women but not in men and female gender and late onset was associated with poorer sexual function.

The limitation of this study is its retrospective design that did not allow us to properly assess preoperative sexual and life quality. That information was not systematically recorded at that time.

\section{Conclusions}

We retrospectively reviewed the files of 55 women with severe HS operated between December 2017 and June 2019. Localized and wide excisions yielded good cosmetic and functional results illustrated by high satisfaction rates on assessment of post-surgical and sexual quality of life. Recurrence rate was high since total excision is difficult to perform in groin and ano-genital areas.

Chronicity and recurrence make HS a psychologically hard-to-live condition. Therefore, management should be holistic and multidisciplinary involving dermatologists, psychologists, gynecologists, sexologists, and any other specialist when necessary. More studies need to be carried out with larger samples to better understand its etiology and characterize the patient population.

\section{Author Contributions}

DS, CT and BH designed the study. DS recruited the subjects, analyzed the data and drafted the manuscript. CT, BH and JPM corrected the manuscript. DS, CT, $\mathrm{BH}$ and JPM all accepted the final version.

\section{Acknowledgements}

To all the patients who accepted to return our questionnaire, without whom this study wouldn't have been done.

\section{Funding Information}

We received no funding or grant for this study.

\section{Conflicts of Interest}

The authors declare no conflict of interest.

\section{References}

[1] Alikhan, A., Lynch, P.J. and Eisen, D.B. (2009) Hidradenitis suppurativa: A Comprehensive Review. Journal of the American Academy of Dermatology, 60, 539-561. https://doi.org/10.1016/j.jaad.2008.11.911

[2] Revuz, J. (2009) Hidradenitis suppurativa. Journal of the European Academy of Dermatology and Venereology, 23, 985-998. https://doi.org/10.1111/j.1468-3083.2009.03356.x

[3] Gulliver, W., Zouboulis, C.C., Prens, E., Jemec, G.B. and Tzellos, T. (2016) Evidence-Based Approach to the Treatment of Hidradenitis suppurativa /Acne Inversa, Based on the European Guidelines for Hidradenitis suppurativa. Reviews in Endocrine and Metabolic Disorders, 17, 343-351. 
https://doi.org/10.1007/s11154-016-9328-5

[4] Slade, D.E.M., Powell, B.W. and Mortimer, P.S. (2003) Hidradenitis suppurativa: Pathogenesis and Management. Journal of Plastic, Reconstructive \& Aesthetic Surgery, 56, 451-461. https://doi.org/10.1016/S0007-1226(03)00177-2

[5] Jemec, G.B.E. (2012) Hidradenitis suppurativa. The New England Journal of Medicine, 366, 158-164. https://doi.org/10.1056/NEJMcp1014163

[6] Saunte, D.M.L. and Jemec, G.B.E. (2017) Hidradenitis suppurativa: Advances in Diagnosis and Treatment. JAMA, 318, 2019-2032.

https://doi.org/10.1001/jama.2017.16691

[7] Deckers, I.E., Dahi, Y., Van der Zee, H.H. and Prens, E.P. (2018) Hidradenitis suppurativa Treated with Wide Excision and Second Intention Healing: A Meaningful Local Cure Rate after 253 Procedures. Journal of the European Academy of Dermatology and Venereology, 32, 459-462. https://doi.org/10.1111/jdv.14770

[8] Wolkenstein, P., Loundou, A., Barrau, K., Auquier, P., Revuz, J. and Dermatology, Q. (2007) Quality of life Impairment in Hidradenitis suppurativa: A Study of 61 Cases. Journal of the American Academy of Dermatology, 56, 621-623.

https://doi.org/10.1016/j.jaad.2006.08.061

[9] Revuz, J.E., Canoui-Poitrine, F., Wolkenstein, P., Viallette, C., Gabison, G., Pouget, F., Poli, F., Faye, O., Roujeau, J.C. and Bonnelye, G. (2008) Prevalence and Factors Associated with Hidradenitis suppurativa: Results from Two Case-Control Studies. Journal of the American Academy of Dermatology, 59, 596-601. https://doi.org/10.1016/j.jaad.2008.06.020

[10] Baker, R. (1991) The Reliability and Criterion Validity of a Measure of Patients' Satisfaction with Their General Practice. Family Practice, 8, 171-177. https://doi.org/10.1093/fampra/8.2.171

[11] Rosen, R. (2000) The Female Sexual Function Index (FSFI): A Multidimensional Self-Report Instrument for the Assessment of Female Sexual Function. Journal of Sex \& Marital Therapy, 26, 191-208. https://doi.org/10.1080/009262300278597

[12] Zouboulis, C.C., Desai, N., Emtestam, L., Hunger, R.E., Ioannides, D., Juhász, I., Lapins, J., Matusiak, L., Prens, E.P. and Revuz, J. (2015) European S1 Guideline for the Treatment of Hidradenitis suppurativa/Acne Inversa. Journal of the European Academy of Dermatology and Venereology, 29, 619-644. https://doi.org/10.1111/jdv.12966

[13] Zouboulis, C.C., Bechara, F.G., Fritz, K., Kurzen, H., Liakou, A.I., Marsch, W.C., Milling, A., Nast, A., Podda, M. and Taube, K.M. (2012) S1 Guideline for the Treatment of Hidradenitis suppurativa /Acne Inversa (ICD-10 Ziffer: L73.2). Journal of the German Society of Dermatology, 10, S1-S31.

https://doi.org/10.1111/j.1610-0387.2012.08006.x

[14] Jemec, G.B., Heidenheim, M. and Nielsen, N.H. (1996) The Prevalence of Hidradenitis suppurativa and Its Potential Precursor Lesions. Journal of the American Academy of Dermatology, 35, 191-194.

https://doi.org/10.1016/S0190-9622(96)90321-7

[15] Fitzsimmons, J.S. and Guilbert, P.R. (1985) A Family Study of Hidradenitis suppurativa. Journal of Medical Genetics, 22, 367-373.

https://doi.org/10.1136/jmg.22.5.367

[16] Williams, S.T., Busby, R.C., DeMuth, R.J. and Nelson, H. (1991) Perineal Hidradenitis suppurativa: Presentation of Two Unusual Complications and a Review. Annals of Plastic Surgery, 26, 456-462.

https://doi.org/10.1097/00000637-199105000-00008 
[17] Chaikin, D.C., Volz, L.R. and Broderick, G. (1994) An Unusual Presentation of Hidradenitis suppurativa: Case Report and Review of the Literature. Urology, 44, 606-608. https://doi.org/10.1016/S0090-4295(94)80072-3

[18] Brown, S.C.W., Kazzazi, N. and Lord, P.H. (1986) Surgical Treatment of Perineal Hidradenitis suppurativa with Special Reference to Recognition of the Perianal Form. British Journal of Surgery, 73, 978-980. https://doi.org/10.1002/bjs.1800731210

[19] Paletta, F.X. (1963) Hidradenitis suppurativa: Pathologic Study and Use of Skin Flaps. Plastic and Reconstructive Surgery, 31, 307-315. https://doi.org/10.1097/00006534-196304000-00001

[20] Wiseman, M.C. (2004) Hidradenitis suppurativa: A Review. Dermatologic Therapy, 17, 50-54. https://doi.org/10.1111/j.1396-0296.2004.04007.x

[21] Hurley, H. (1989) Dermatologic Surgery, Principles and Practice, Marcel Dekker ed., New York.

[22] Sartorius, K., Lapins, J., Emtestam, L. and Jemec, G.B.E. (2003) Suggestions for Uniform Outcome Variables When Reporting Treatment Effects in Hidradenitis suppurativa. British Journal of Dermatology, 149, 211-213. https://doi.org/10.1046/j.1365-2133.2003.05390.x

[23] Kouris, A., Platsidaki, E., Christodoulou, C., Efstathiou, V., Dessinioti, C., Tzanetakou, V., Korkoliakou, P., Zisimou, C., Antoniou, C. and Kontochristopoulos, G. (2016) Quality of Life and Psychosocial Implications in Patients with Hidradenitis suppurativa. Dermatology, 232, 687-691. https://doi.org/10.1159/000453355

[24] Janse, I.C., Deckers, I.E., van der Maten, A.D., Evers, A.W.M., Boer, J., van der Zee, H.H., Prens, E.P. and Horváth, B. (2017) Sexual Health and Quality of Life Are Impaired in Hidradenitis suppurativa: A Multicentre Cross-Sectional Study. British Journal of Dermatology, 176, 1042-1047. https://doi.org/10.1111/bjd.14975

[25] Alavi, A., Anooshirvani, N., Kim, W.B., Coutts, P. and Sibbald, R.G. (2015) Quality-of-Life Impairment in Patients with Hidradenitis suppurativa: A Canadian Study. American Journal of Clinical Dermatology, 16, 61-65. https://doi.org/10.1007/s40257-014-0105-5

[26] Ulrich, A., Hildebrandt, U. and Ulrich, J. (2014) Acne Inversa: Influence of Associated Factors in the Extent of the Disease and the Result of Surgery. Der Hautarzt, 65, Article No. 623. https://doi.org/10.1007/s00105-014-2839-7

[27] Mehdizadeh, A., Hazen, P.G., Bechara, F.G., Zwingerman, N., Moazenzadeh, M., Bashash, M., Sibbald, R.G. and Alavi, A. (2015) Recurrence of Hidradenitis suppurativa after Surgical Management: A Systematic Review and Meta-Analysis. Journal of the American Academy of Dermatology, 73, S70-S77.

https://doi.org/10.1016/j.jaad.2015.07.044

[28] Alavi, A., Farzanfar, D., Lee, R.K. and Almutairi, D. (2018) The Contribution of Malodour in Quality of Life of Patients with Hidradenitis suppurativa. Journal of Cutaneous Medicine and Surgery, 22, 166-174.

https://doi.org/10.1177/1203475417745826 


\section{List of Abbreviations}

ASEX: Arizona Sexual Experience scale

FSFI: Female Sexual Function Index

HiSCR: Hidradenitis Suppurativa Clinical Response

HS: Hidradenitis suppurativa

IIEF: International Index of Erectile Function

PGA: Physician Global Assessment

QoL: Quality of life

SSQ: Surgical satisfaction questionnaire 